\title{
Performance of a Pilot-scale Multitube Membrane Module under Coal- Derived Syngas for Hydrogen Production and Separation
}

\author{
Bernardo Castro-Dominguez ${ }^{1}$, Ivan P. Mardilovich, Rui Ma, Nikolaos K. Kazantzis, Anthony G. Dixon, \\ Yi Hua Ma \\ Center for Inorganic Membrane Studies, Department of Chemical Engineering, Worcester Polytechnic \\ Institute, 100 Institute Road, Worcester, MA 01609, USA.
}

\begin{abstract}
Pilot-scale tests generate information about the performance of energy systems and thus help in the deployment of new technologies. This work aims at demonstrating the pilot-scale application of palladium-based membrane technology for the purification of $\mathrm{H}_{2}$. A multitube membrane module with a total permeable area of $1050 \mathrm{~cm}^{2}$ was tested under actual coal-derived syngas. The module was composed of seven membranes with a $\mathrm{Pd} / \mathrm{Au} / \mathrm{Pd}$ layered structure supported on PSS tubes. The membranes were arranged with one membrane at the center and six equally distributed around it. The membranes had a composition of $7 \mu \mathrm{m} \mathrm{Pd}$ and $0.4 \mu \mathrm{m} \mathrm{Au}$ and a cumulative He leak of $<0.01 \mathrm{~cm}^{3} / \mathrm{min} / \mathrm{bar}$ before testing. The module was operated at $450^{\circ} \mathrm{C}, 12.6 \mathrm{bar}$ and $10 \mathrm{lb} / \mathrm{h}$ of desulfurized syngas provided by a gasification unit and enriched with $\mathrm{H}_{2}$ to $34 \%$. The module showed a stable $\mathrm{H}_{2}$ permeance of $16.2 \mathrm{Nm}^{3} \mathrm{~m}^{-2} \mathrm{~h}^{-1} \mathrm{bar}^{-0.5}$ throughout 840 hours. The produced $\mathrm{H}_{2}$ purity was in the range of 99.87-98\%. An $\mathrm{H}_{2}$ production of 6 $\mathrm{lb} /$ day and recovery of $64 \%$ were achieved, representing a significant development in the field. The scalability and industrial applicability of this technology was successfully demonstrated. Furthermore, a CFD model illustrated different physical phenomena associated with this multitube configuration.
\end{abstract}

\section{Keywords}

Hydrogen production; Multitube membrane module; Pd-based Composite Asymmetric Membranes; Coalderived Syngas; Computational Fluid Dynamics

\footnotetext{
1 Author to whom correspondence should be sent; Address: 100 Institute Road, Department of Chemical Engineering, Worcester Polytechnic Institute, Worcester, MA 01609-2280, USA; E-mail address: bcastrodominguez@,wpi.edu / bcastrodominguez@,gmail.com , Phone number: +1-508-8315666.
} 


\section{Introduction}

As an energy carrier and as a fuel, hydrogen is a chemical that could potentially assume a key role in the design and operation of future versatile energy systems. Some of the benefits of building a hydrogen economy include: environmentally-friendly properties when oxidized as a fuel, availability of multiple $\mathrm{H}_{2}$ transportation methods (road, rail, ship, pipeline, etc.), multiple storage configurations (unlike electricity), applicability as fuel or for electrical generation, and potential production through multiple sources/pathways [1]. Currently, the production of $\mathrm{H}_{2}$ relies heavily on fossil fuel-based sources such as natural gas and coal, but can potentially extend to renewable sources such as biomass. According to the U.S. Office of Energy Efficiency and Renewable Energy [2], methane steam reforming accounts for 95\% of the hydrogen produced in the United States; simultaneously, it is expected that coal gasification will be deployed in the mid-term time frame. To achieve the proposed hydrogen economy, the production of pure $\mathrm{H}_{2}$ is essential whilst reducing the generation of greenhouse gases such as carbon dioxide. It is important to point out that most applications require an $\mathrm{H}_{2}$ purity in the range of $99.99 \%$ to $99.9995 \%$ and that $\mathrm{H}_{2}$ separation and purification account for half of the production costs $[3,4]$. Palladium-based membrane technology has been shown to be effective in the generation of ultrapure molecular $\mathrm{H}_{2}$ at high fluxes, as well as facilitating the capture of $\mathrm{CO}_{2}$ when integrated as a catalytic membrane reactor (CMR) [4,5].

Palladium membrane technology can exhibit superior economic performance compared to conventional technology options under specific market and regulatory conditions when integrated within different $\mathrm{H}_{2}$ production and/or energy systems [6,7]. For instance, Ma et al. [6] showed that the economic performance profile of a hydrogen production plant (HP) utilizing CMR technology could not be perceived as competitive when assessed against the incumbent technology options based on pressure swing adsorption (PSA) in the absence of any regulatory action on $\mathrm{CO}_{2}$ emissions. Nonetheless, in the presence of future regulatory action on $\mathrm{CO}_{2}$ emissions, it was demonstrated that superior technoeconomic performance characteristics emerge for CMR technology when integrated into the aforementioned process systems, namely ones associated with: i) a significant reduction (26\%) of total capital investment costs compared to conventional PSA-based HP plants; and ii) an enhancement of the overall economic performance under various economic metrics and carbon prices.

Large-scale membrane-based separation processes require high available surface areas to achieve the desired production rates. In order to reduce costs in membrane technology while increasing the permeation rate, it is necessary to increase the ratio of the surface area of the membranes to the volume of the module holding them. Therefore, a multitube membrane unit raises the amount of membrane surface area that can be accommodated in a given volume such as in the case of hollow fiber membrane modules [8]. Only a very limited number of large-scale operating tests, however, have been conducted under 
realistic conditions. Mardilovich et al. studied the performance of pilot-scale $\mathrm{Pd}$ and Pd-alloy membranes under actual coal-derived syngas [9]. Thirteen membranes were tested for a cumulative time of 4275 hours and classified according to their composition in four groups: pure Pd, Pd-Au, Pd-Pt and Pd-Au-Pt. The membranes produced an $\mathrm{H}_{2}$ quality in the range of $99.95-99.00 \%$ and displayed excellent stability; nevertheless, a permeance drop occurred when the membranes were tested under syngas conditions, possibly due to the presence of sulfur present in the lines of the system. Furthermore, it was found that Au-containing membranes improved the robustness of the membranes by repairing any in-situ formation of pinholes. Adding gold to the membranes has been shown to be beneficial as their $\mathrm{H}_{2}$ permeance recoverability improves when poisoned by $\mathrm{H}_{2} \mathrm{~S}$ and other contaminants present in syngas [10,11]. Furthermore, as reported throughout the literature $[9,10,11,12]$, the $\mathrm{H}_{2}$ permeabilities of $\mathrm{Pd} / \mathrm{Au}$ membranes have been shown to be higher than those of pure Pd membranes.

According to Lu et al. [13], the current state of affairs for the application of Pd membranes shows only small scale applications. Indeed, few multitube membrane modules have been evaluated and the associated results presented in the literature for $\mathrm{H}_{2}$ purification. For instance, Tosti et al [14] demonstrated the design of a finger-like permeator tube reactor useful for ethanol reforming. The module was capable of producing $6 \mathrm{~L} \mathrm{~min}^{-1}$ of $\mathrm{H}_{2}$ utilizing 19 Pd-Ag membranes with a thickness of 50-60 $\mu \mathrm{m}$ and a total surface area of $1490 \mathrm{~cm}^{2}$. Diniz da Costa et al. [15] reported the design of a cobalt-based silica multitube membrane reactor. The module was used for the water-gas-shift reaction producing a $\mathrm{H}_{2}$ purity of $98 \%$. Notice that the produced $\mathrm{H}_{2}$ flux and the total surface area of the module were not reported in the study. Parsley et al. [16] reported the evaluation results of a carbon molecular sieve multitube membrane module for the separation of $\mathrm{H}_{2}$ from actual coal derived syngas under water-gas-shift reaction conditions. The module consisted of 86 tubes with a surface area of $7600 \mathrm{~cm}^{2}$ and was capable of producing $\mathrm{H}_{2}$ with $90 \%$ purity. Moreover, numerical simulations on single tube membrane units have been widely reported in the literature [17,18], but to the authors knowledge only a few multitube membrane models have been previously published. For instance, Coroneo et al. [19] studied a module containing three membranes and baffles. The purpose of the reported model was to demonstrate the effect of baffles which divided the module in sections reducing concentration polarization.

In economic terms, as described by Ma et al. [20], scaling up (increasing the surface area of the active membrane) is the next step towards the actual deployment of this membrane technology. Certainly, various techno-economic assessments have envisioned, as a key element, the use of multitube membrane modules capable of holding large membrane surface areas [6, 7]. Furthermore, these multitube membrane systems require optimization and a thorough analysis in order to maximize their technical benefits which could result in better economic performance outcomes in the presence of technological 
challenges and irreducible uncertainties in fuel markets and the regulatory landscape. For instance, physical phenomena such as mass and heat transfer limitations can significantly reduce the $\mathrm{H}_{2}$ throughput, which could significantly influence the economic performance profiles of hydrogen plants [6,7,20]. In light of the aforementioned characteristics, the present work aims at demonstrating the development, scale up and field testing of a seven-tube palladium-based membrane module operating under actual coalderived syngas and industrial settings, and producing $\mathrm{H}_{2}$ at purity levels above $98 \%$. Furthermore, a thorough analysis on the physical phenomena occurring inside the multitube membrane module was performed to illustrate essential differences between single and multitube membrane systems. This work contains in Section 2 the experimental procedures for membrane synthesis, characterization of the multitube module and specifications of the numerical simulation, followed by the description of the main results in Section 3. Section 4 contains a discussion based on the results of the numerical simulation and finally, some concluding remarks are offered in Section 5.

\section{Methodology}

\subsection{Membrane Preparation and Module Design}

The palladium membranes developed at Worcester Polytechnic Institute (WPI) and previously reported in the literature $[9,10,11,21,22,23]$ were scaled up and replicated in order to synthesize eight new membranes. Eight porous stainless steel (PSS) tubes purchased from Mott Metallurgical Corp. were used for the synthesis of the membranes. Each porous tube had a surface area of $150 \mathrm{~cm}^{2}$ and dimensions of 15 in. in length and $0.5 \mathrm{in}$. OD. Each porous support had a Media Grade of $0.5 \mu \mathrm{m}$ and was welded to a capped end on one side and to a stainless steel tube on the other. All supports were cleaned in an ultrasonic bath utilizing propanol followed by an oxidation step at $600{ }^{\circ} \mathrm{C}$ for 12 hours in air $[23,24,25]$.

The pre-oxidized supports were subject to grading using two types of slurries composed of preactivated alumina particles. The first grading step consisted of coarse particles with sizes in the range of 1-3 $\mu \mathrm{m}$; while fine grading introduced particles of $0.6 \mu \mathrm{m}$. The grading layers were glued with palladium as previously described $[22,24,25]$. The membranes were then activated and electroless plated to create a dense Pd layer of the graded supports; for further reference on this procedure please refer to the pertinent literature $[25,26]$. Afterwards, a gold layer was deposited on top of the palladium in order to improve the stability and recoverability of the membranes, as reported by Chen et al. [11]. An additional layer of Pd was finally plated on top of Au to create a multilayered composite membrane. The thickness of the Pd and $\mathrm{Au}$ layers was estimated through gravimetric measurements and each step of the synthesis was characterized by an He leak test. Figure 1 shows the different thickness of the stages in the synthesis of 
the composite membranes; on average the membranes had a thickness layer of $5.4 \mu \mathrm{m} \mathrm{Pd}, 0.4 \mu \mathrm{m} \mathrm{Au}$ and $1.6 \mu \mathrm{m} \mathrm{Pd}$, with an intermediate grading layer of $2.5 \mu \mathrm{m}$.

Figure 3 shows the average He leak at each step of the synthesis. As purchased, each support had an He flux of $200 \mathrm{~L} / \mathrm{min}$ at one bar $\Delta \mathrm{P}$ and it was reduced to a cumulative (all seven membranes) He flux of $<0.01 \mathrm{~cm}^{3} / \mathrm{min}$. The supports showed half the He flux after oxidation and further reduction to 56 $\mathrm{cm}^{3} /$ min after grading. Grading is a critical step in the formation of a defect-free Pd membrane since it reduces the uneven pore size distribution of the support and smooths its surface, allowing the formation of an even Pd thickness after plating [22,26]. The total permeable surface area of the seven membranes is $1050 \mathrm{~cm}^{2}$. The additional synthesized membrane was tested at WPI under controlled conditions with pure $\mathrm{H}_{2}$ for comparison purposes. Moreover, it is important to mention that the membranes were synthesized layer-by-layer, creating well defined Pd and Au layers. Nonetheless, as shown in previous studies [9,11], alloying occurs in-situ when the temperature is increased under the operating conditions considered in this work

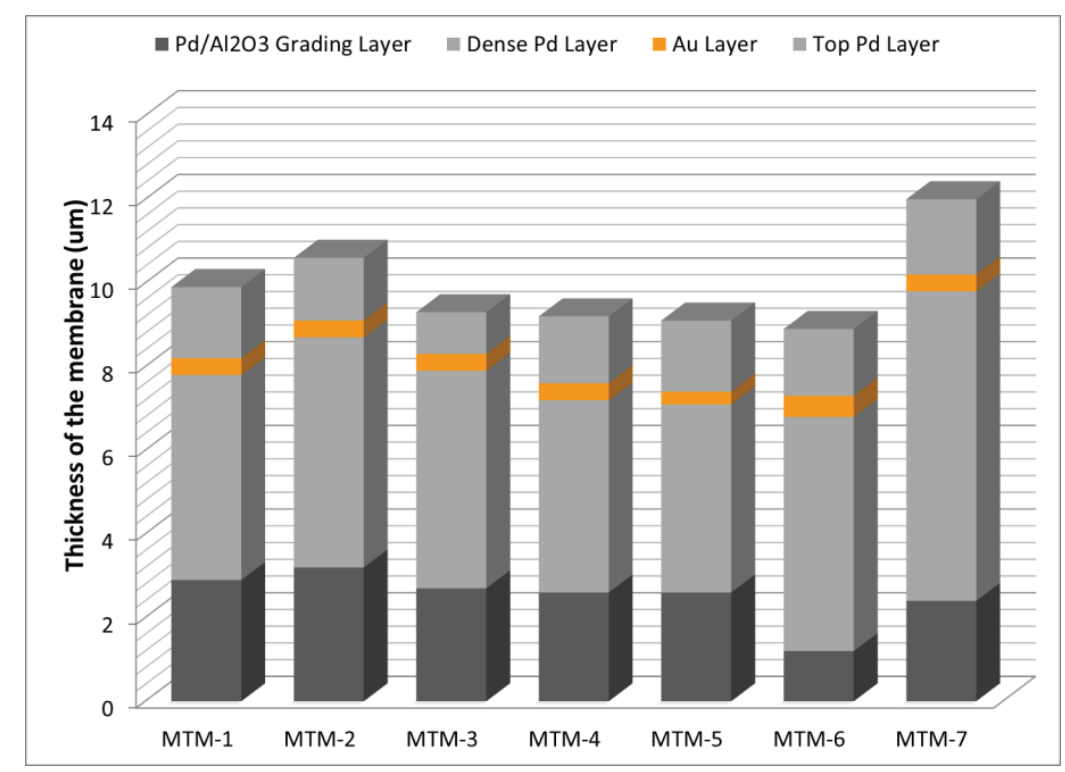

Figure 1. Composition of the multilayered composite membranes used in the present study. 


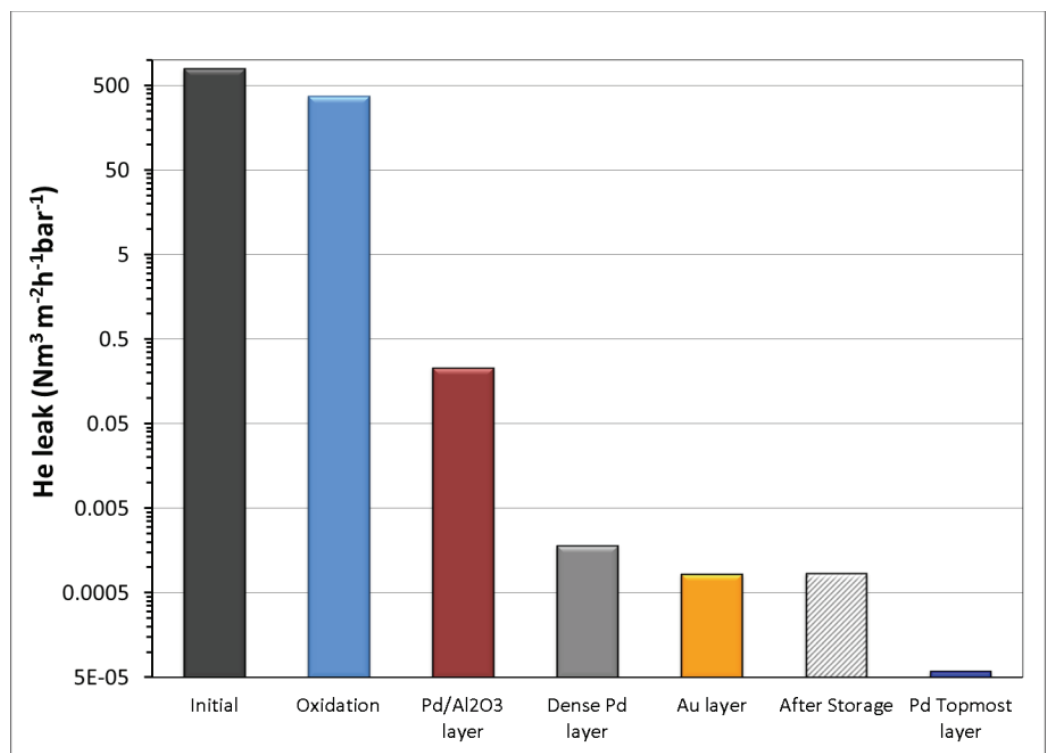

Figure 3. Average He leak through the Pd/Au/Pd membranes throughout each synthesis step.

\subsection{Coal Derived Syngas}

The multitube membrane module containing the seven $\mathrm{Pd} / \mathrm{Au} / \mathrm{Pd}$ membranes was installed in the WPI-MTR (Worcester Polytechnic Institute - Membrane Technology Research) skid at the National Carbon Capture Center in Wilsonville, Al. [27] and it is shown in Figure S1 (Supplementary Materials). The module was purged with pure $\mathrm{N}_{2}$ and its operating pressure was increased to $>12$ bar and the temperature was increased to $450^{\circ} \mathrm{C}$. It is important to mention that the module showed no leak while testing the module seal. After reaching the operating temperature, a mixture of 35:65 $\mathrm{H}_{2} / \mathrm{N}_{2}$ was fed to the system, followed by the actual coal-derived syngas.

Syngas was produced by an air-blown transport-integrated gasification (TRIG ${ }^{\mathrm{TM}}$ ) system that used powder river basin (PRB) coal. The raw syngas was treated to reduce particulates to $0.1 \mathrm{ppv}, \mathrm{CO}$ to $<1 \%$ and $\mathrm{H}_{2} \mathrm{~S}$ to $<1 \mathrm{ppm}$, followed by $\mathrm{H}_{2}$ enrichment of $30-40 \%$ to increase the $\mathrm{H}_{2}$ partial pressure in the module and thus improve the driving force for permeation. The feed had an average composition of $\mathrm{H}_{2}$ : $34 \%, \mathrm{~N}_{2}: 55 \%, \mathrm{CO}<1 \%, \mathrm{CO}_{2}: 10 \%, \mathrm{H}_{2} \mathrm{O}$ : balance as described previously in the pertinent literature [27]. The composition of the feed, permeate and retentate was monitored by a gas chromatograph (model Siemens Maxum II, columns: HysepN and HA-MS for $\mathrm{H}_{2}, \mathrm{~N}_{2}, \mathrm{CO}$, and $\mathrm{CH}_{4}$; HysepN and HysepQ for $\mathrm{CO}_{2}$ and $\mathrm{H}_{2} \mathrm{~S}$; detector was a TCD), while the flow rates were measured periodically using a rotameter. Notice that the syngas at $160-180^{\circ} \mathrm{C}$ was additionally heated through a pipe-coil that surrounds the module as shown in Figure S1 (Supplementary Materials). For further information about the configuration of the rig and the gasifier, please refer to previously reported work $[9,10,27]$. Finally, it is 
important to mention that postmortem membrane characterization was not performed due to logistic issues with the membrane module.

\subsection{Computational Fluid Dynamics Model}

A simplified computational fluid dynamics (CFD) model for the multitube membrane module was developed, to study the physics of the system under similar conditions to those presented in the experiment. The model consisted of a 3-D representative geometry subject to the continuity equation (Eq. 1) and the equation of motion (Eq. 6). COMSOL Multiphysics 5.0 was used to solve the equations within the proposed geometry and "Transport of Concentrated Species" was utilized as the physics of this system.

$$
\nabla \cdot \mathrm{j} i+\rho \mathrm{u} \cdot \nabla w i=\mathrm{R} i
$$

where $\mathrm{ji}$ represents the diffusion of species $i$, $\rho u \bullet \nabla$ wi convection and Ri the rate of $\mathrm{H}_{2}$ flux across the membrane. Diffusion of species $i$ is assumed as:

$$
\begin{gathered}
\mathrm{ji}=-\rho \operatorname{Dim} \nabla w i+\rho w i \operatorname{Dim} \nabla M n M n \\
\operatorname{Dim}=1-w i k \neq i x k \operatorname{Dik} \\
M n=i w i M i-1
\end{gathered}
$$

The mass flux of the system was defined by Equation 5:

$$
\mathrm{N} i=\mathrm{j} i+\rho \mathrm{u} w i
$$

The equation of motion (Eq. 6 and Eq. 7) was used to describe the flow of syngas inside the module:

$$
\begin{gathered}
\rho \mathrm{u} \cdot \nabla \mathrm{u}=\nabla \cdot-p \mid+\mu \nabla \mathrm{u}+\nabla \mathrm{u} T+F \\
\nabla \cdot \rho \mathrm{u}=0
\end{gathered}
$$

The change in density as a function of the mass fractions in the module was defined as:

$$
\rho=p R T i w i M i-1
$$

In contrast with previous models which applied source and sink terms to simulate transport across the membrane, this model used a reacting boundary flux based on Sieverts' Law (Eq. 9):

$$
-\mathrm{n} \cdot \mathrm{N} i=\mathrm{PH} 2 \mathrm{pH} 2 \text { shell }-\mathrm{pH} 2 \text { tube }
$$


Where $\mathrm{n} \cdot \mathrm{Ni}$ represents the $\mathrm{H}_{2}$ flux across the membrane, $\mathrm{PH} 2$ the permeance of the membrane, and pH2shell and $\mathrm{pH} 2$ tubethe $\mathrm{H}_{2}$ partial pressure at the shell and at the tube, respectively.

The simulation model used in this work has the following assumptions:

1) Laminar flow

2) Isothermal system

3) Gas flow was symmetrical along the membranes

4) Outlet had a pressure of 12.6 bar with no viscous stress

A fine mesh was defined containing 2,000,000 elements (Figure 5). A direct solver with two segregated groups was adopted for the calculation. A super computer with 130 GB RAM memory was used in this work.

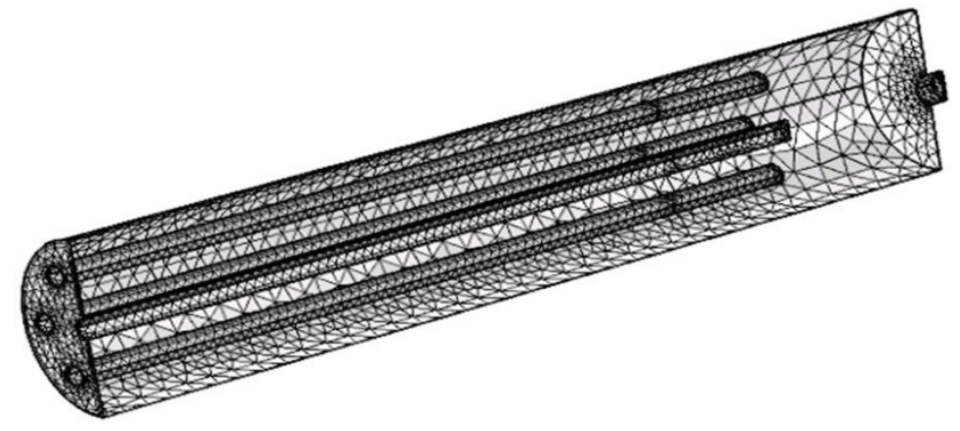

Figure 5. Geometry of the model and mesh.

\section{Results}

\subsection{Synthesis of the membrane module and set-up}

After $\mathrm{Au}$ deposition, the membranes were stored at $40^{\circ} \mathrm{C}$ for 6 months under air. The He leak of the membranes after this period changed as shown in Figure 7. Notice that some membranes presented an increased He leak while others decreased. It is suspected that overall, all membranes had an He leak increase and that the membranes which showed a reduction in He permeation were mainly affected by moisture blocking the defects present on the surface of the membranes. Due to the change in the He leak, a topmost layer was formed on top of the Pd before the module was assembled with seven of the eight membranes and subsequently shipped to the NCCC facilities. Notice that the replicability of synthesizing these membranes is effectively demonstrated, having a standard deviation in the Pd layer thickness of 0.9 $\mu \mathrm{m}$ or about $10 \%$. 


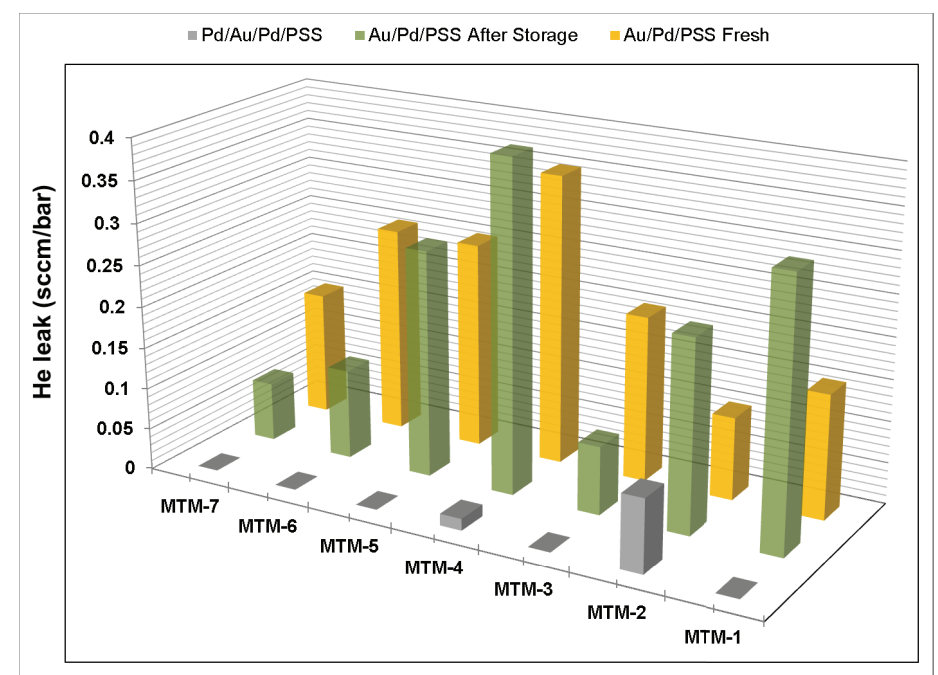

Figure 7. He leak of each membrane as fresh Pd/Au, after storage and final leak.

The multitube membrane module was designed to hold seven $\mathrm{Pd} / \mathrm{Au} / \mathrm{Pd}$ membranes. The module had one membrane located at the center of the module and six equally spaced membranes surrounding it. The surrounding membranes were kept at $1.31 \mathrm{in}$. from the central membrane and were distributed in a hexagonal arrangement; the membrane module was designed to have a length of $38 \mathrm{in}$., as shown in Figure S2 (Supplementary Materials). The axial positions of the membranes varied in order to allow Swagelok connections within the confinement of the $4.5 \mathrm{in.}$ OD shell of the module. For instance, the connection of the central membrane was at a longer position than the surrounding ones; while the position of the remaining connections was alternated between shorter and medium lengths, as shown in Figure S2 (Supplementary Materials). A holder was placed on the tip of the membranes to maintain the configuration of the membranes and potentially act as a baffle for better mixing of the gases. The multitube membrane module had a shell-and-tube configuration and was sealed utilizing an assembly consisting of flanges, studs and clamps (Grazyloc 4 in.) which can be seen in Figure S2 (Supplementary Materials).

\subsection{Permeation Test Results}

As in previously reported gasification runs at NCCC [9,10], approximately $10 \mathrm{lb} / \mathrm{h}$ of gas with a variable composition was fed to the module as shown in Figure 9. At first, the module was tested under a 35:65 $\mathrm{H}_{2} / \mathrm{N}_{2}$ mixture for $100 \mathrm{~h}$ followed by flowing coal-derived syngas which was composed mainly of $\mathrm{H}_{2}, \mathrm{CO}_{2}, \mathrm{~N}_{2}$ and $\mathrm{CH}_{4}$ for $\sim 700 \mathrm{~h}$. 
The initial evaluation of the performance of the membrane module was based on its $\mathrm{H}_{2}$ permeance or pressure normalized flux $(P H 2)$, produced $\mathrm{H}_{2}$ purity and $\mathrm{H}_{2}$ recovery $(\mathrm{R})$ as defined in Equations 10-12:

$$
\begin{aligned}
& P H 2=F H 2, \text { permout } A \text { pH2ave }- \text { pH2perm } \\
& \text { Purity }=F H 2, \text { permout } F i \text {, permout } \bullet 100 \\
& R=F H 2, \text { permout } F H 2, \text { feed } \bullet 100
\end{aligned}
$$

Here $F H 2$, feed and $F H 2$, permout are the $\mathrm{H}_{2}$ flow rates for the feed and the permeate outlet streams, respectively. $A$ is the permeable surface area of the membranes, $p H$ 2ave and $p H 2$ perm are the $\mathrm{H}_{2}$ partial pressures inside the module shell and in the permeate side, respectively. Given the number of data points, $p H$ 2avewas approximated as the average of the $\mathrm{H}_{2}$ partial pressure of the feed $(p H 2$, feed $)$ and the retentate $(p H 2$, ret $)$.

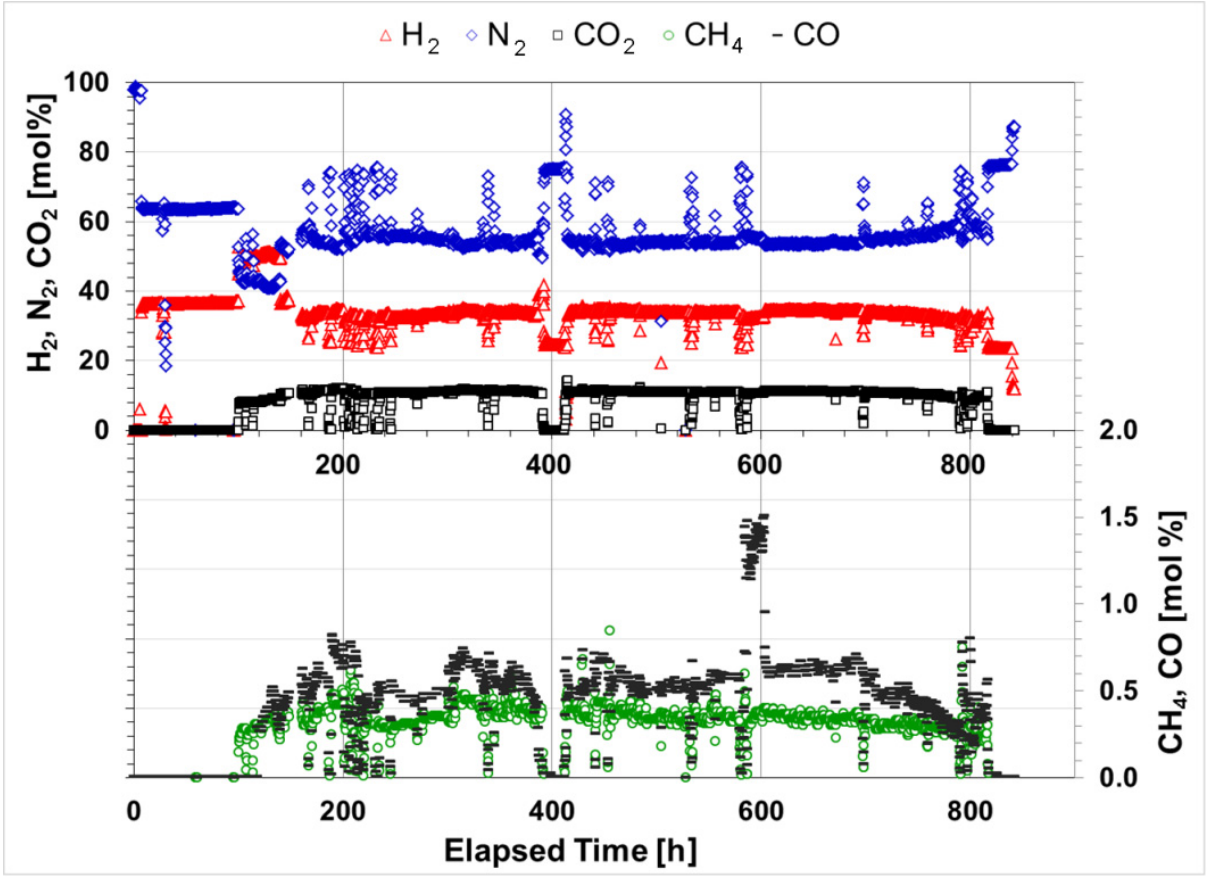

Figure 9. Composition of the gas mixture fed to the module as a function of time. 
The $\mathrm{H}_{2}$ permeance and purity of the module are displayed as functions of time as shown in Figure 11. At first, the membrane module showed a permeance in the range of 7-10 $\mathrm{Nm}^{3} \mathrm{~m}^{-2} \mathrm{~h}^{-1} \mathrm{bar}^{-0.5}$ when tested under $\mathrm{H}_{2} / \mathrm{N}_{2}$ mixture as depicted in Figure 11 in solid black data points. When syngas was fed into the module, a slight oscillation in permeance was observed during the first $100 \mathrm{~h}$, followed by a steady performance. Notice that the average permeance under $\mathrm{H}_{2} / \mathrm{N}_{2}$ mixture and syngas were found to be of 8.8 and $8.2 \mathrm{Nm}^{3} \mathrm{~m}^{-2} \mathrm{~h}^{-1} \mathrm{bar}^{-0.5}$, respectively indicating a $7 \%$ reduction in permeance under syngas conditions. The maximum flux achieved by these membranes was $6 \mathrm{lb} /$ day of $\mathrm{H}_{2}$. It is important to mention that the module displayed constant properties (Figure 11) even though the continuous changes in the feed stream were present.

Furthermore, the additional synthesized membrane MTM-8 with the same dimensions and characteristics was tested in the facilities of Worcester Polytechnic Institute under clean and pure $\mathrm{H}_{2}$. The $\mathrm{H}_{2}$ permeation test is shown at 350 and $450^{\circ} \mathrm{C}$ in Figure 13, displaying permeances of 75 and $80 \mathrm{Nm}^{3} \mathrm{~m}^{-2} \mathrm{~h}^{-}$ ${ }^{1}$ bar $^{-0.5}$, respectively. In terms of flux the membrane showed a maximum productivity of $1.03 \mathrm{lb} /$ day at a pressure difference of 0.35 bar. Moreover, a hypothetical multitube model composed of pure freestanding Pd membranes with a thickness of $7.4 \mu \mathrm{m}$, and tested under pure $\mathrm{H}_{2}$ at $450^{\circ} \mathrm{C}$ was calculated to have a theoretical $\mathrm{H}_{2}$ permeance of $63 \mathrm{Nm}^{3} \mathrm{~m}^{-2} \mathrm{~h}^{-1} \mathrm{bar}^{-0.5}$. In addition, the single tube membranes previously tested under similar syngas conditions at NCCC [9], showed $\mathrm{H}_{2}$ permeances between $5-15 \mathrm{Nm}^{3} \mathrm{~m}^{-2} \mathrm{~h}^{-1}$ bar $^{-}$ 0.5 and under pure $\mathrm{H}_{2}$ at WPI permeances between $10-29 \mathrm{Nm}^{3} \mathrm{~m}^{-2} \mathrm{~h}^{-1} \mathrm{bar}^{-0.5}$. The reduction of the cumulative $\mathrm{H}_{2}$ flux across this multitube membrane is attributed to i) the fast depletion of $\mathrm{H}_{2}$ along the membrane module; ii) the mass transfer resistance caused by the boundary layer formed at the surface of the membrane; iii) the permeance inhibition caused by $\mathrm{CO}, \mathrm{CO}_{2}$ and steam [28]; and finally iv) the potential sulfur content on the feed lines of the system at NCCC as previously reported [10]. At these operating conditions, the module presented a depletion of $\mathrm{H}_{2}$ along the membrane module hindering the actual value of the permeance. For instance, the feed stream presented an average $\mathrm{H}_{2}$ partial pressure of 4.3 bar and it was reduced to 2.5 bar at the retentate outlet or by a factor of about 1.7. This reduction in driving force is not linear, as assumed in the present estimation of the permeance shown in Figure 11. Furthermore, radial mass transfer limitations cause concentration polarization which occurs when $\mathrm{H}_{2}$ diffusion is slower than the permeation rate. Indeed, the presence of a $\mathrm{H}_{2}$ depleted boundary layer can significantly reduce the displayed $\mathrm{H}_{2}$ flux across the membranes [29]. 


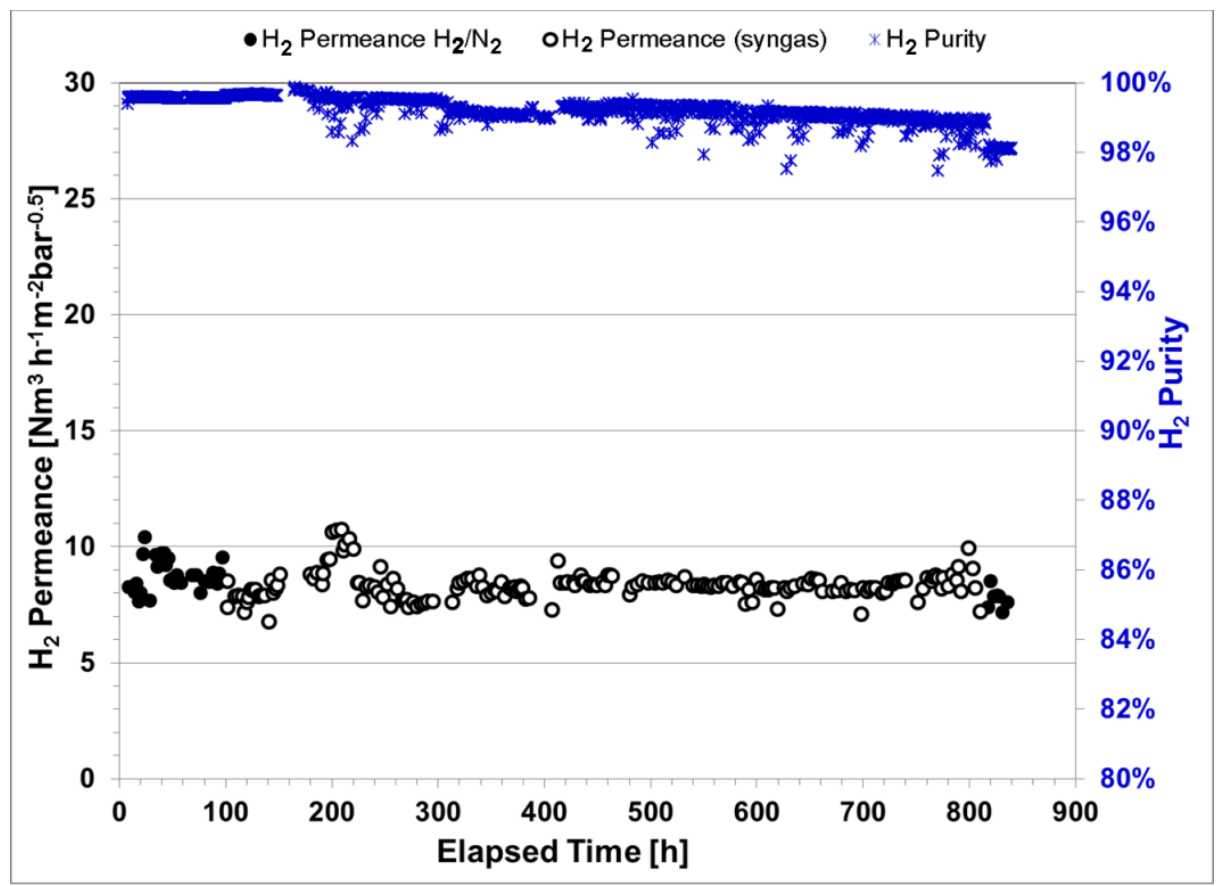

Figure 11. Hydrogen permeance and purity profiles of the multitube membrane module at NCCC under $\mathrm{H}_{2} / \mathrm{N}_{2}$ and syngas at $450^{\circ} \mathrm{C}$ and $12.6 \mathrm{bar}$.

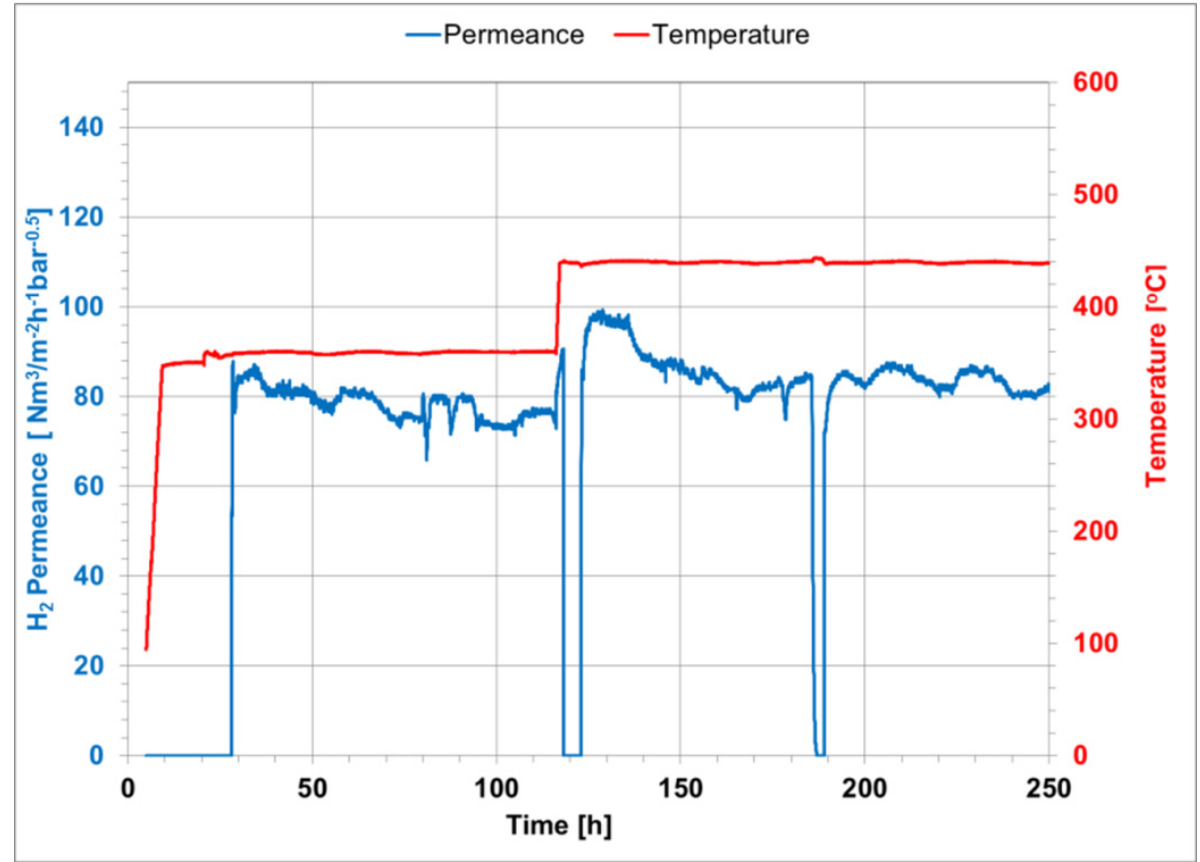

Figure 13. Hydrogen permeance of membrane MTM-8 at WPI under pure $\mathrm{H}_{2}$ at $450^{\circ} \mathrm{C}$ and 1 bar.

A non-linear mathematical analysis was performed in order to approximate more accurately the permeance of this module. By neglecting the presence of uneven radial mass distribution and mass 
transfer resistances, but including the nonlinearity of the $\mathrm{H}_{2}$ partial pressure within the module, the permeance of the membrane module was estimated by solving the differential equation shown in Eq. 13. $F H 2$ is the local $\mathrm{H}_{2}$ flow rate across the membrane module, $A$ the total permeable surface area, and $p H 2$ is the local $\mathrm{H}_{2}$ partial pressure, which is defined as the product of the total operating pressure and the local $\mathrm{H}_{2}$ mole fraction in the retentate (Eq. 14). The initial conditions of this ODE were specified as the given average experimental values such as feed gas composition and flow rate.

The permeance was adjusted accordingly in order to match the displayed $\mathrm{H}_{2}$ recovery, retentate composition and total $\mathrm{H}_{2}$ flow rate at the outlet of the permeate stream. Notice that given the complexity of this calculation, the permeance estimate was shown only for the average properties rather than for every single point through time as the data shown in Figure 11. The $\mathrm{H}_{2}$ permeance of the membrane module was estimated to be $16.2 \mathrm{Nm}^{3} \mathrm{~m}^{-2} \mathrm{~h}^{-1} \mathrm{bar}^{-0.5}$, which is considered to be a more accurate value than that obtained using Eq. 13, because $p_{H 2}$ on the retentate side was allowed to vary nonlinearly, as shown in Figure 15.

$$
d F H 2 d A=P H 2 \bullet p H 2-p H 2 \text { perm }
$$

$$
\text { pH2=ptotalFH2,ret Fi,ret }
$$

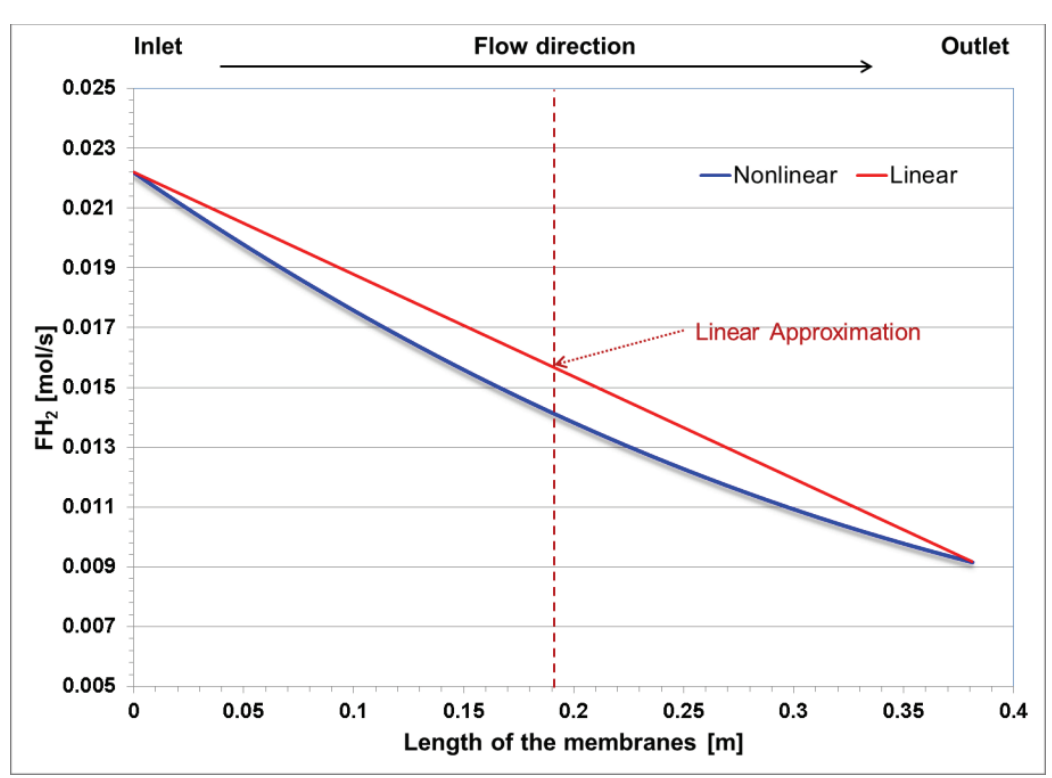

Figure 15. Axial distribution of the retentate $\mathrm{H}_{2}$ flow rate, showing the difference between the linear and refined mathematical approximation 
The presence of $\mathrm{CO}$ is well known to affect the permeance of $\mathrm{Pd}$ membranes [28]. Competitive absorption of $\mathrm{CO}$ within the active sites available reduces the potential solution of more $\mathrm{H}_{2}$ molecules and consequently inhibits their performance under ideal conditions. It is important to mention that other contaminants present in syngas such as sulfur have been shown to reduce the permeance of $\mathrm{Pd}$ membranes. Our group [9,10] showed in single tube Pd and Pd-Alloy membranes that even traces of sulfur can significantly reduce the $\mathrm{H}_{2}$ permeance; nevertheless, the presence of the Au aids in the recovery of the lost permeance by exposing the membranes to pure $\mathrm{H}_{2}$ at $450^{\circ} \mathrm{C}$. Other contaminants such as $\mathrm{Na}, \mathrm{Mg}, \mathrm{O}, \mathrm{S}, \mathrm{Hg}$ and $\mathrm{C}$ were previously found on the surface of the Pd membranes tested under coal derived syngas [10].

The $\mathrm{H}_{2}$ purity produced by these membranes began at $99.5 \%$ under $\mathrm{H}_{2} / \mathrm{N}_{2}$ and underwent a sudden increase to $99.63 \%$ when syngas was fed and up to $99.87 \%$ after being tested for 67 hours in syngas conditions. Afterwards, the purity of the module decreased steadily reaching a minimum purity of $98.84 \%$ after 670 hours under syngas conditions. Notice that at the end of the test, the $\mathrm{H}_{2}$ purity was 98.13\% under a $\mathrm{H}_{2} / \mathrm{N}_{2}$ mixture. It is important to mention that the lifetime of these Pd-Au-Pd membranes is significantly improved compared to pure Pd membranes, whose life time is estimated at $200 \mathrm{~h}$ under industrial settings [9,30]. Additionally, the single tube membrane tests previously reported [9] showed $\mathrm{Pd} / \mathrm{Au}$ composite membranes displaying $\mathrm{H}_{2}$ purities in the range of $99.95-99.8 \%$ with a lifetime of 535 hours for a $\mathrm{Pd} / \mathrm{Au} / \mathrm{Pt}$ membrane. Furthermore, the $\mathrm{H}_{2}$ purity profiles achieved by this technology throughout the testing time clearly outperform the ones exhibited by conventional technologies such as cryogenic distillation [22,31]. Additionally, assuming that the purity of the permeated $\mathrm{H}_{2}$ decreases linearly with time, as shown by Figure 11, it is expected that this module will produce $\mathrm{H}_{2}$ with a purity of $91 \%$ after a year of continuous operation. Furthermore, once the defects of the membranes become significant, they can be regenerated by surface cleaning and palladium replating, reducing the leak of the membranes and extending their total lifetime [24].

Figure 17 shows the $\mathrm{H}_{2}$ recovery achieved under the aforementioned conditions as a function of time. Notice that when the membrane module was under $\mathrm{H}_{2} / \mathrm{N}_{2}$ at the beginning of the test, the average recovery was estimated to be $52 \%$. Under syngas conditions, the average $\mathrm{H}_{2}$ recovery increased to $64 \%$. This effect can be explained by analyzing the $\mathrm{H}_{2}$ flow rate of the feed stream. As mentioned before, 10 $\mathrm{lb} / \mathrm{h}$ of gas was fed into the module, but the different compositions between the $\mathrm{H}_{2} / \mathrm{N}_{2}$ mixture and syngas caused changes in the molar flow of $\mathrm{H}_{2}$. For instance, $10 \mathrm{lb} / \mathrm{h}$ of gas feed is equivalent to $88 \mathrm{~mol} / \mathrm{h}$ of $\mathrm{H}_{2}$ fed for a $(35 / 65) \mathrm{H}_{2} / \mathrm{N}_{2}$ mixture, but it is $79 \mathrm{~mol} / \mathrm{h}$ of $\mathrm{H}_{2}$ fed for syngas enriched to $35 \%$; there is a $10 \%$ difference in $\mathrm{H}_{2}$ molar flow rate between the $\mathrm{H}_{2} / \mathrm{N}_{2}$ mixture and syngas. Furthermore, the space velocity 
of the gases is different for $\mathrm{H}_{2} / \mathrm{N}_{2}$ and for syngas. It is estimated that $5.5 \mathrm{~m}^{3} / \mathrm{h}$ of $\mathrm{H}_{2} / \mathrm{N}_{2}$ was fed into the system at standard conditions, while syngas had a volumetric flow rate of $4.9 \mathrm{~m}^{3} / \mathrm{h}$.

Indeed, having a higher feed flow rate directly affects the recovery achieved (Figure 19) by the module since higher membrane surface area is needed to accomplish the transport of all $\mathrm{H}_{2}$ molecules fed, even though the $\mathrm{H}_{2}$ partial pressure is similar. Higher feed flow rate utilizes the available surface area of the membranes better, even though recovery is reduced. In other words, obtaining a low $\mathrm{H}_{2}$ recovery directly implies that the membranes were occupied evenly and that the displayed permeance is closer to the permeance under pure $\mathrm{H}_{2}$. High recoveries, such as those presented in this work, do not show the maximum $\mathrm{H}_{2}$ flux that the module can achieve, since it is hindered by $\mathrm{H}_{2}$ depletion within the unit. Figure 19 shows the module's $\mathrm{H}_{2}$ recovery as a function of the $\mathrm{H}_{2}$ feed flow rate. An exponential decay is observed and a plateau can be predicted at a recovery of $\sim 40 \%$.

Notice that the maximum theoretical $\mathrm{H}_{2}$ recovery achievable by the module is $<90 \%$, which can be improved by reducing the permeate $\mathrm{H}_{2}$ partial pressure with the presence of sweep gas in the permeate side and/or by increasing the retentate pressure. Additionally, it is expected that the presence of baffles could improve mixing and avoid mass transfer resistances, improving further the $\mathrm{H}_{2}$ recovery of the module [18].

The successful results obtained from the 7-membrane module tests reported here demonstrate that the good performance previously found $[9,10]$ for a single membrane tube can be scaled up. These results are promising for the future development of palladium composite membrane modules with more tubes and hence greater permeation area. 


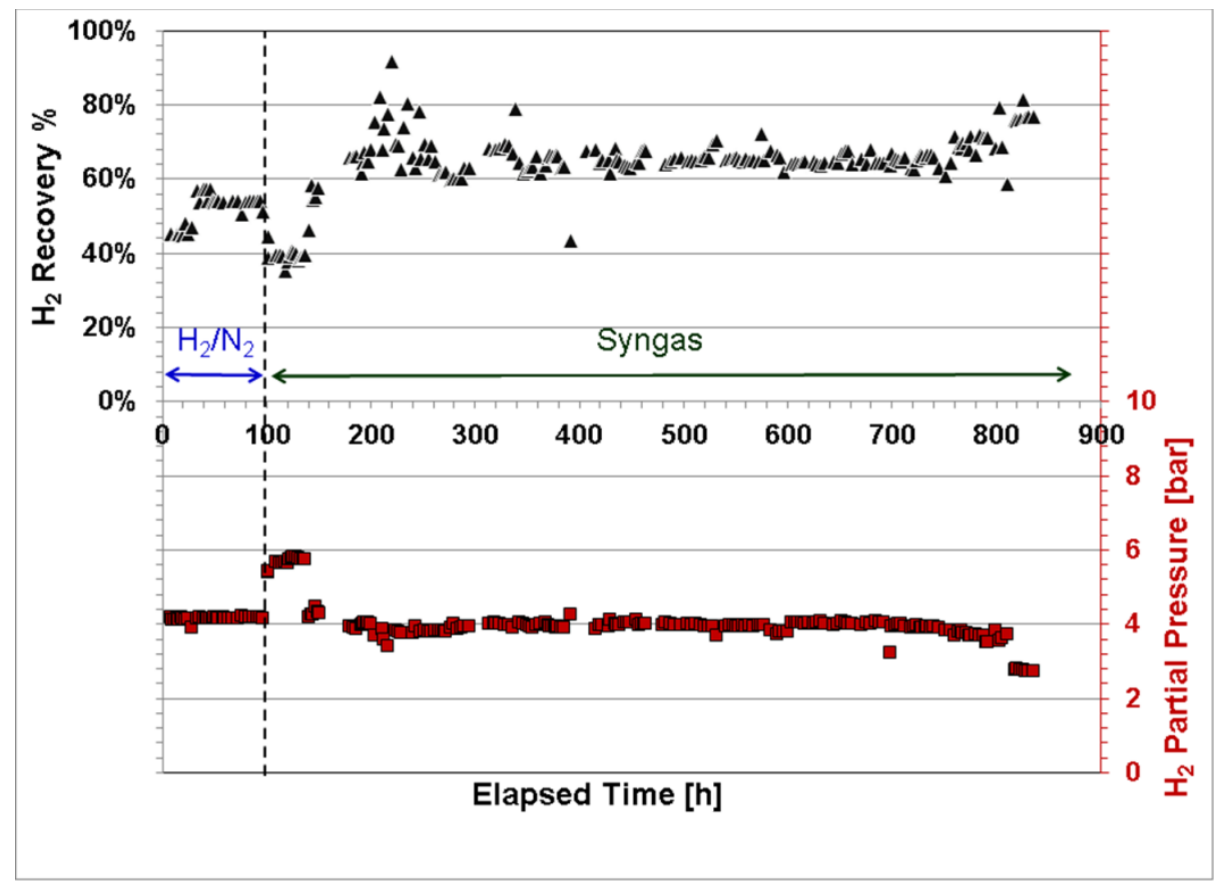

Figure 17. Hydrogen recovery and $\mathrm{H}_{2}$ partial pressure of the multitube membrane module testedat NCCC.

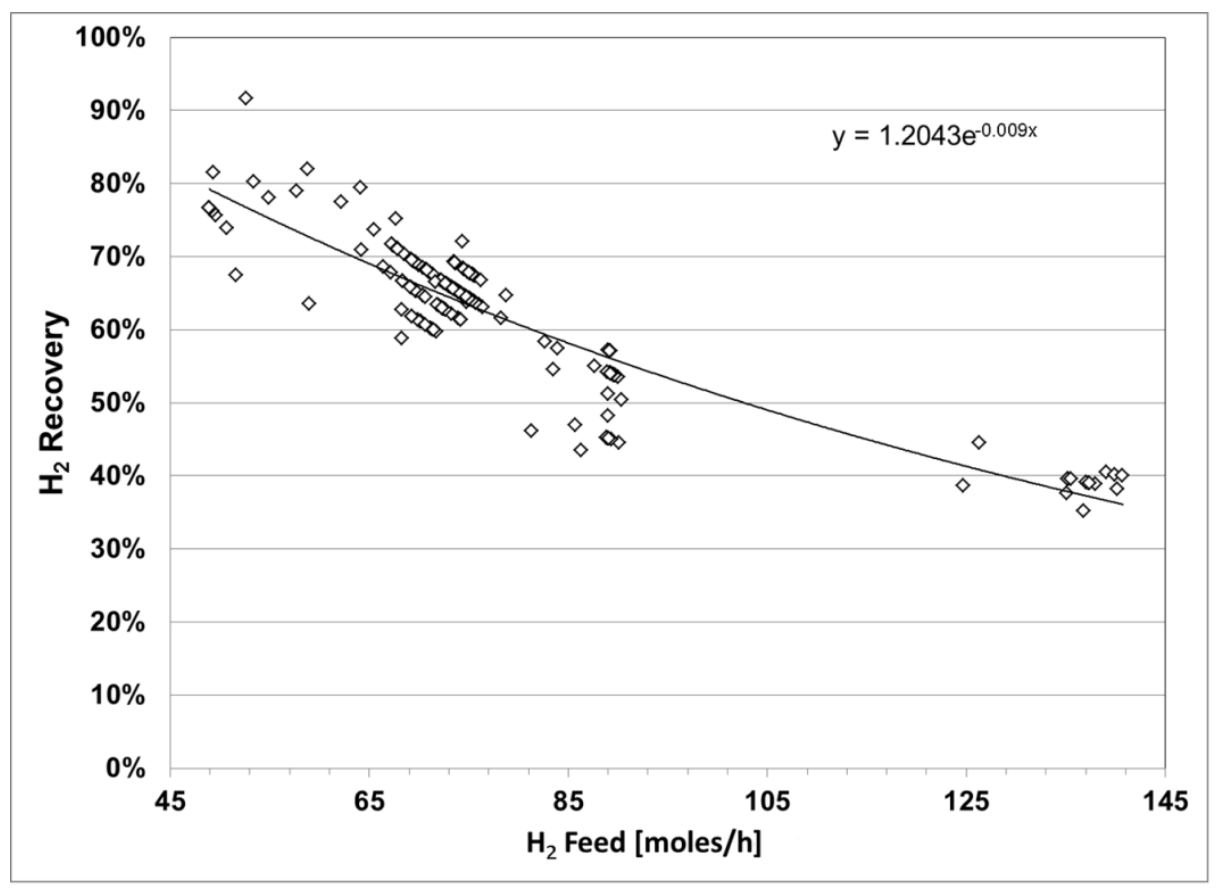

Figure 19. Hydrogen recovery as a function of the feed $\mathrm{H}_{2}$ flow rate. 


\section{Discussion}

Through a computation fluid dynamics (CFD) model, a compelling visualization of the mass transport phenomena occurring inside the membrane module was generated. The CFD model generated data at different permeances, predicting the performance of the actual system as shown in Table 1. Key parameters (permeation rate, $\mathrm{H}_{2}$ content at the retentate and recovery) were most accurately projected by the model, assuming a permeance of $16 \mathrm{Nm}^{3} \mathrm{~h}^{-1} \mathrm{~m}^{-2} \mathrm{bar}^{-0.5}$; it is important to highlight that this value is close to the 16.2 obtained earlier. The results presented in this work have an error of $2 \%$, which could be further reduced by refining further the numerical mesh, as depicted in Figure 21. Certainly, although Figure 21 does not show the results to be mesh-independent; given the purpose of this discussion and the lack of computational power, the analysis of the results with this accuracy is certainly justified.

Table 1: Comparison of CFD data with experimental data.

\begin{tabular}{|l|l|l|l|l|}
\hline & Experimental & $\begin{array}{l}\text { Simulation } \\
\text { Permeance=14 } \\
\mathrm{Nm}^{3} \mathrm{~h}^{-1} \mathrm{~m}^{-2} \mathrm{bar}^{-0.5}\end{array}$ & $\begin{array}{l}\text { Simulation } \\
\text { Permeance=16 } \\
\mathrm{Nm}^{3} \mathrm{~h}^{-1} \mathrm{~m}^{-2} \mathrm{bar}^{-0.5}\end{array}$ & $\begin{array}{l}\text { Simulation } \\
\text { Permeance=18 } \\
\mathrm{Nm}^{3} \mathrm{~h}^{-1} \mathrm{~m}^{-2} \mathrm{bar}^{-0.5}\end{array}$ \\
\hline Permeate flow rate (L/min) & 17.47 & 17.77 & 18.99 & 20.04 \\
\hline Retentate $\mathrm{H}_{2}$ Percentage (\%) & 22.35 & 23.30 & 22.34 & 21.50 \\
\hline Recovery (\%) & 37 & 35.37 & 38.06 & 40.39 \\
\hline
\end{tabular}

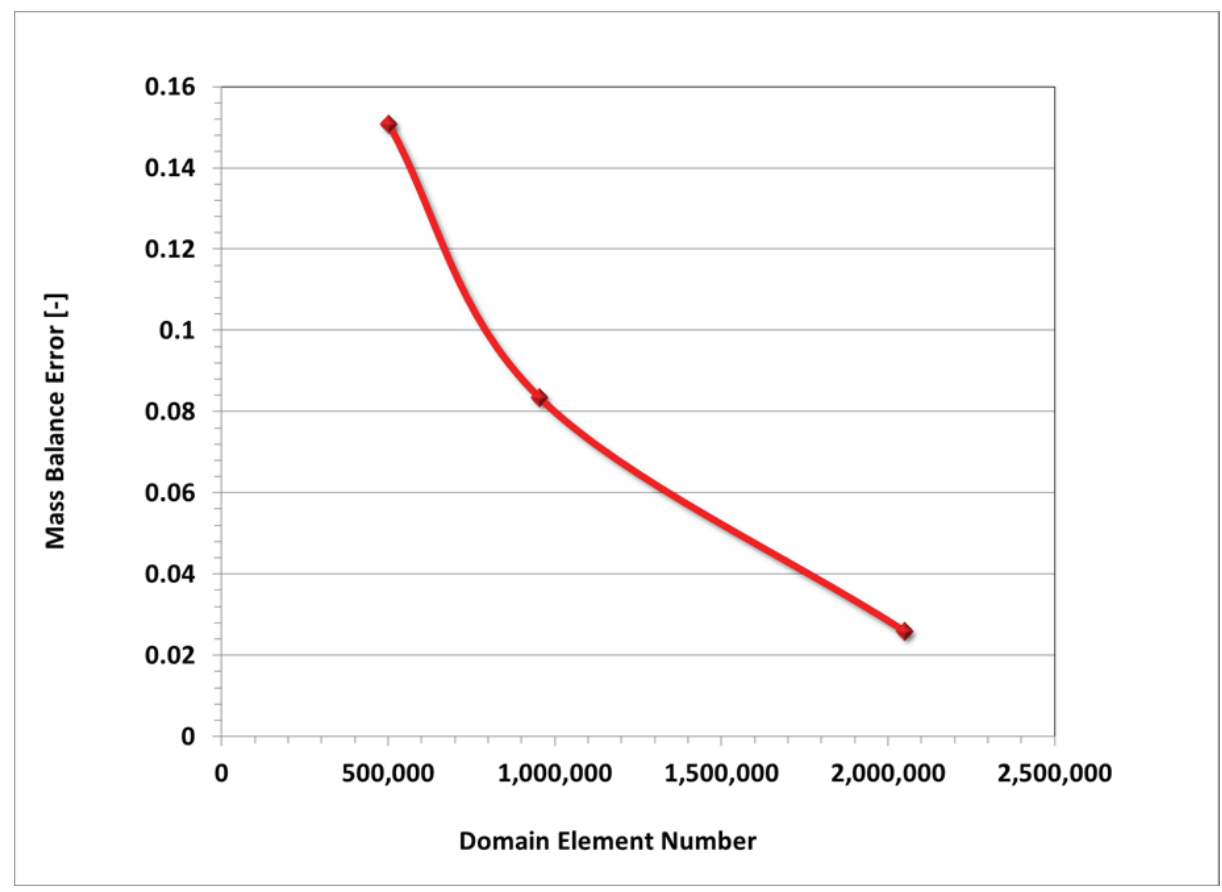

Figure 21. Mass balance error at different mesh refinements. 
The CFD model generated representative $\mathrm{H}_{2}$ concentration profiles inside the multitube membrane model as shown in Figure 23. Syngas is fed on the right side of the picture and exits the multitube module on the left side of the picture. The axial $\mathrm{H}_{2}$ concentration profile (Figure 23a) shows syngas with a high $\mathrm{H}_{2}$ concentration on at the entrance (red), which gradually reduces when approaching the exit of the module. The radial $\mathrm{H}_{2}$ concentration profile (Figure 23b) changed axially. For instance, close to the syngas feed side, an even radial $\mathrm{H}_{2}$ distribution is depicted (red); nonetheless, downstream, radial distribution gradients become more apparent. In particular, a $\mathrm{H}_{2}$ depleted region (blue) adjacent to the membrane surfaces is clearly observed, while an increased $\mathrm{H}_{2}$ concentration appears between the membrane tubes. These radial concentration differences cause the aforementioned concentration polarization effect.
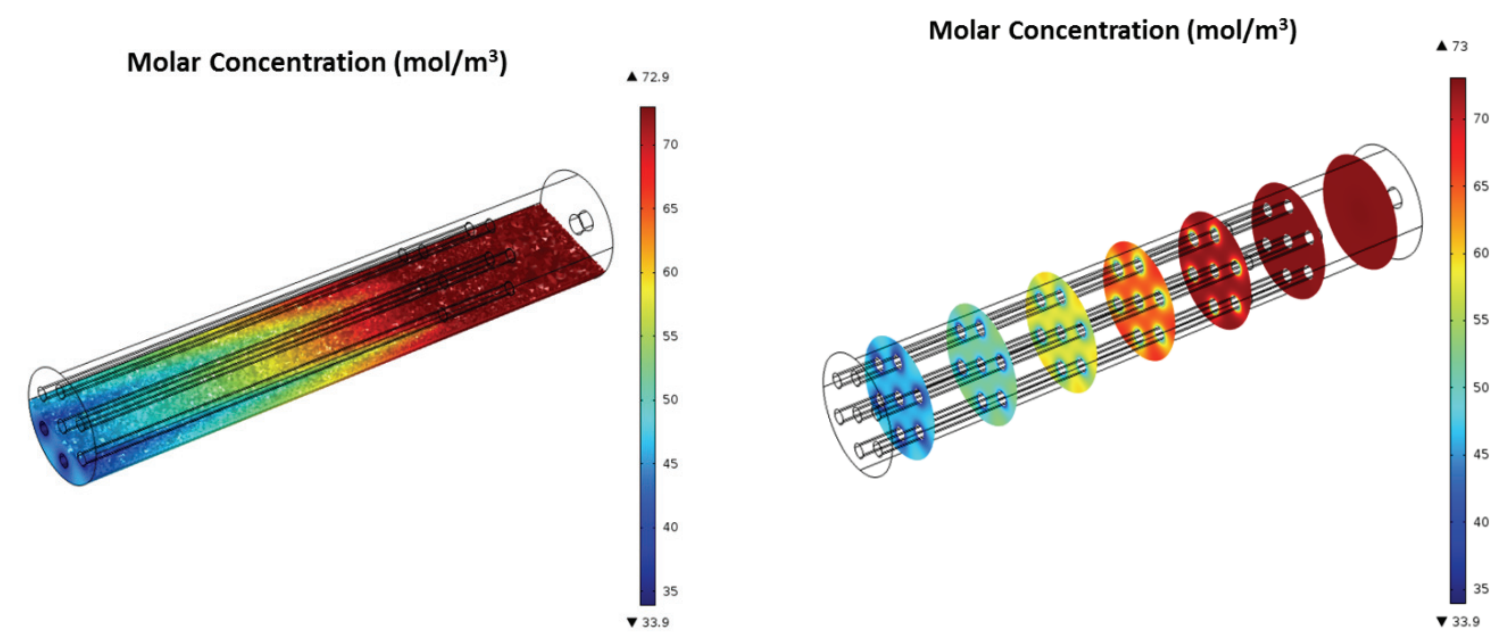

Figure 23. a) Axial and b) radial $\mathrm{H}_{2}$ concentration profile inside the retentate of the multitube membrane module.

Based on the visualization presented in Figure 23, it is possible to infer that multitube membrane systems differ with single tube systems in two main aspects: i) multitube modules have higher membrane surface area to volume ratio and ii) not all membranes operate evenly. High surface area to volume ratio is beneficial in terms of productivity, as these architectures can generate higher amounts of $\mathrm{H}_{2}$ than single tube modules, notably shown in hollow fiber membrane units [32]. Nonetheless, increasing the membrane surface area in a constraint volume raises issues of cleaning, design and operation.

The uneven operation of the membranes is analyzed by comparing the productivity of each membrane within the module. The membranes are numbered from 1 to 7 , as shown in Figure 25, and their productivity normalized by the total system output or total $\mathrm{H}_{2}$ flux. The bar chart in Figure 25 shows 
variations in the productivity of all tubes; nevertheless, the variation among tubes 2 to 7 can be explained by the numeral error of the simulation. Tube number 1 , on the other hand, shows a slightly reduced productivity, compared to the surrounding membranes. In order to explain this phenomenon, three regions are defined in the cross sectional view of the module (Figure 25): $\alpha$ region represents the area between the wall of the module and the surface of membranes 2 to $7, \beta$ is the area surrounding membrane 1 , and $\gamma$ is the zone entangled by the outer tubes and the wall of the module.

Membrane tube 1 has a reduced productivity due to the competition for $\mathrm{H}_{2}$ among adjacent membrane tubes. In other words, the local $\mathrm{H}_{2}$ concentration at zone $\beta$ is shared among membrane 1 and its surrounding counterparts. In contrast, the surrounding tubes have an "exclusive" region denoted by the $\alpha$ zone. This area has little to no competition for $\mathrm{H}_{2}$ with other membranes, and therefore, it appears to be preferentially depleted compared to other regions. It is important to mention that the area comprising $\alpha$ is lower than $\beta$, and therefore, $\beta$ is less prone to depletion. Zone $\gamma$ is shared by two neighboring membranes positioned externally, making competition less intense than $\beta$ and also less exclusive than $\alpha$. Therefore, this $\gamma$ zone contains the highest $\mathrm{H}_{2}$ content radially. As the flow moves downstream, $\mathrm{H}_{2}$ in the $\gamma$ region will preferentially diffuse towards the depleted $\alpha$ zone, due to a higher concentration gradient, and then towards membranes. This effect allows membranes 2-7 to have higher $\mathrm{H}_{2}$ productivity than membrane 1 .

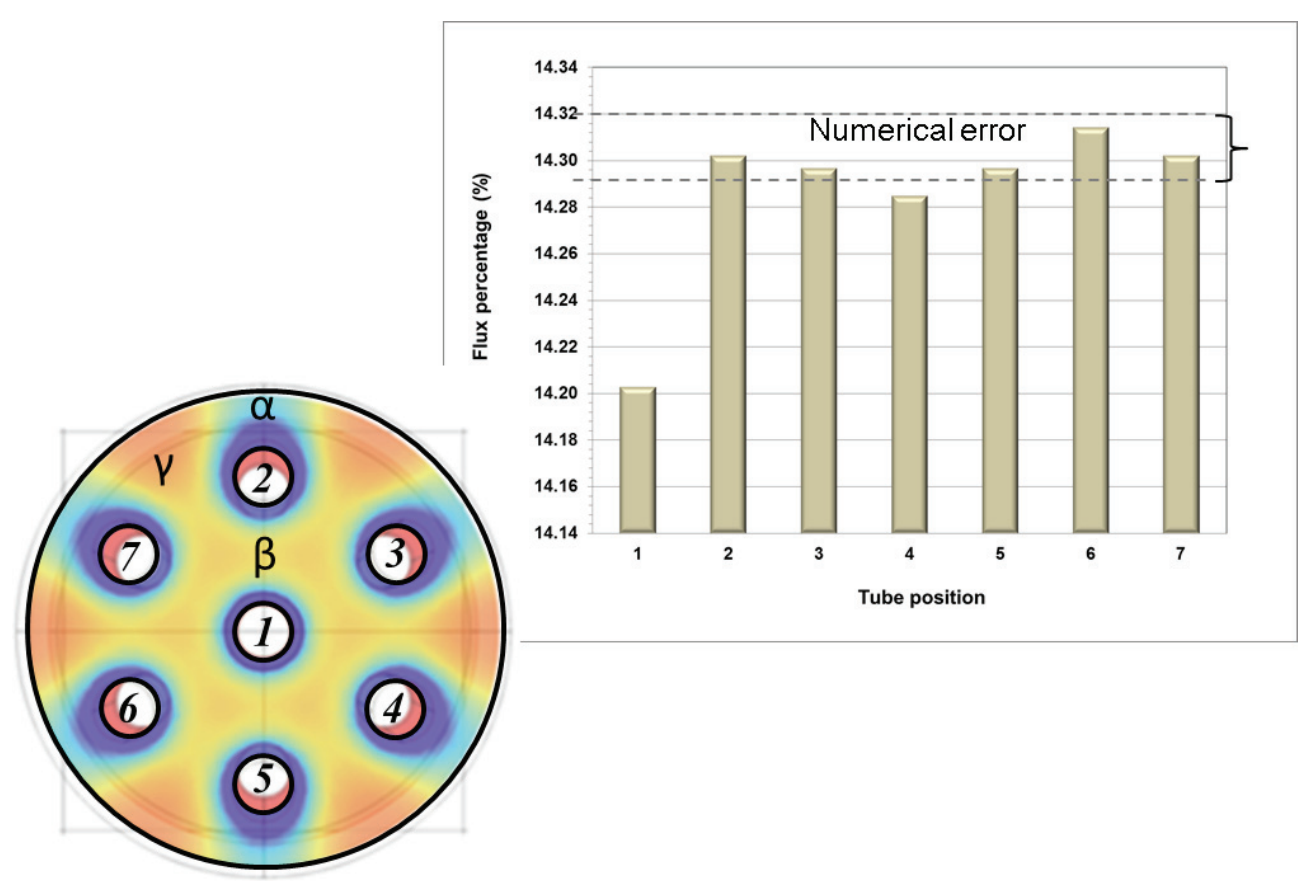

Figure 25. Radial $\mathrm{H}_{2}$ distribution and single membrane performance of the multitube membrane module. 
To support this hypothesis, the $\mathrm{H}_{2}$ permeation rate of the central membrane and that of a surrounding one is comparatively analyzed axially, as shown in Figure 27. The origin of the x-axis is defined as the tip of the membranes and it is the closest point to the feed stream. The flux across a single point on the surface of the membrane was computed along the membrane length (x-axis). It is important to mention that the outer membrane was analyzed in four different sections, designated by the "zone" normal to its surface. The central membrane was analyzed at the points where its surface faces other surrounding membranes directly, as shown in the schematic in Figure 27. In other words, the "central", " $\beta$ " and " $\alpha$ " permeation points always lined up in a straight line, while " $\gamma$ " points remained at $90^{\circ}$ from the " $\beta$ " point.

To begin the analysis of Figure 27, it is important to recognize that at distances smaller than the origin, no $\mathrm{H}_{2}$ flux occurs as it belongs to the non-permeable stainless steel caps of the membranes; therefore, a sudden increase in flux can be appreciated afterwards. Further downstream, all points show the largest permeation rates, as syngas contains the largest amount of $\mathrm{H}_{2}$ at this location. Subsequently, the permeation rate is reduced consistently until syngas exits the module.

The flux across the different points shows a similar trend, but with different magnitude. Let us compare those points that share the $\beta$ zone, which include the "central" and " $\beta$ " points. These permeationpoints show a similar flux magnitude and both comprise the lowest flux among the points analyzed. Indeed, as mentioned previously, the $\mathrm{H}_{2}$ contained in the $\beta$ zone is removed and shared by two adjacent membranes, causing a reduced driving force for permeation. The " $\gamma$ " points show a higher flux than those points sharing the $\beta$ zone. Although, the $\gamma$ zone is shared by two membranes like $\beta$, competition is less prominent since this " $\gamma$ " point does not have a parallel membrane surface that competes for the $\mathrm{H}_{2}$ available. Furthermore, the " $\gamma$ " point is constantly supplied with $\mathrm{H}_{2}$ that diffuses from local $\mathrm{H}_{2}$ enriched spots depicted in red-orange in Figure 25 and Figure 27. Point " $\alpha$ " appears to be the most effective spot surrounding an externally placed membrane. The lack of competition for $\mathrm{H}_{2}$ allows these zones to be effectively depleted at first, generating a "black hole" which attracts $\mathrm{H}_{2}$ from the $\gamma$ zones. The significant concentration gradient between the $\alpha$ and $\gamma$ zones, induces diffusion to the noncompetitive region, thus allowing higher permeation rates.

Through these simulation results, it is possible to conclude that these multitube membrane units differ from single tube modules and that special consideration needs to be addressed while designing them. The model presented in this work showed symmetry which significantly simplified the analysis; nonetheless, a change in flow pattern due to the presence of baffles and/or the location of the feed and retentate, still represents a significant challenge. Furthermore, this work shows that through a detailed CFD analysis, it is possible to improve the design of the modules and further optimize their operation. 
Finally, through a "localized membrane analysis", such as the one presented in this work, it is possible to predict deteriorations on specific membranes and/or sections of the membranes within multitube membrane units. Defects on these membranes, which are usually generated by usage, can be replaced or mechanically fixed [24].

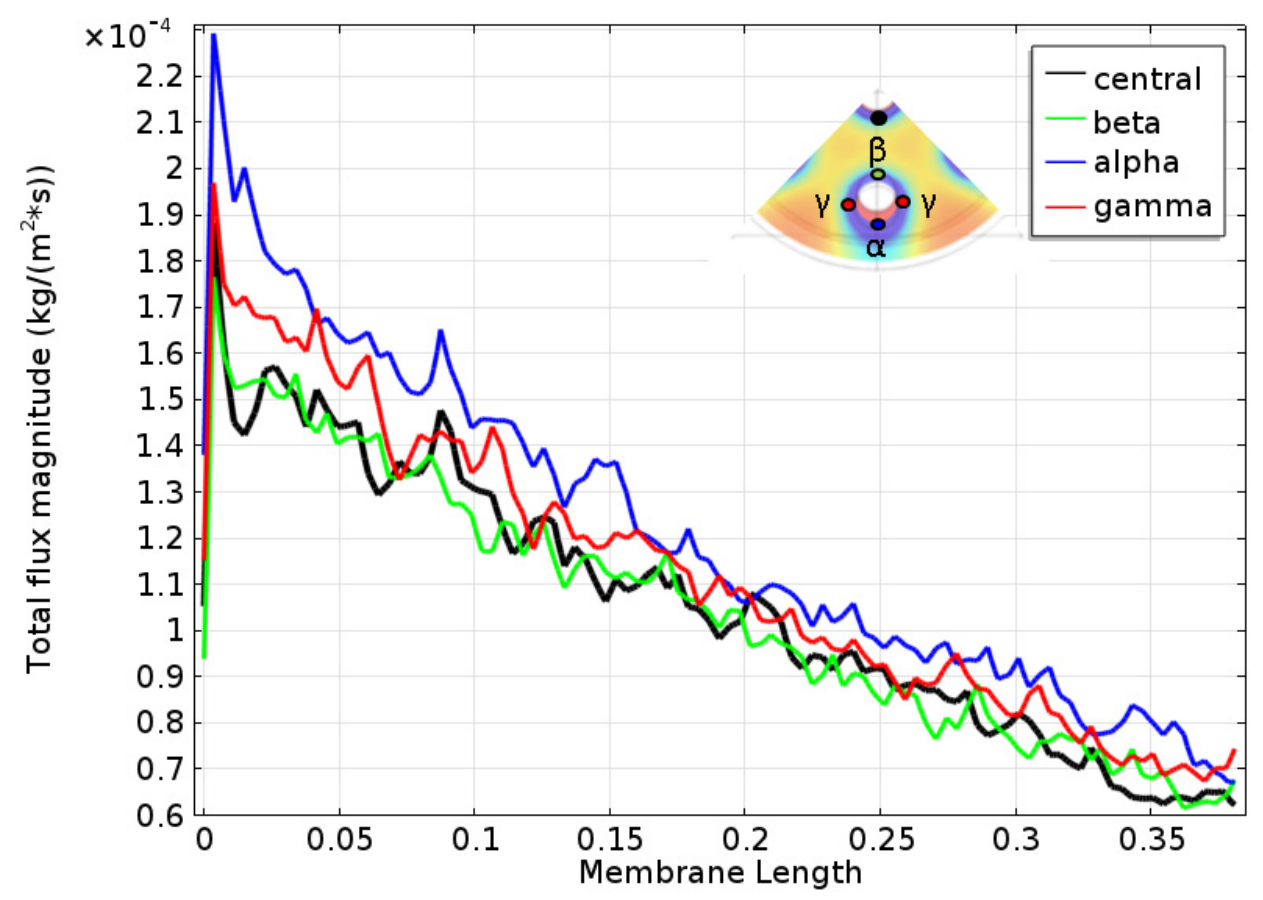

Figure 27. Hydrogen flux along the membranes at different points around the membranes.

\section{Concluding Remarks}

A multitube membrane module using seven membranes was tested in actual coal derived syngas at NCCC, demonstrating the high robustness and excellent physical integrity of composite membranes. The membranes were synthesized over pretreated porous stainless steel supports to form composite asymmetric $\mathrm{Pd} / \mathrm{Au} / \mathrm{Pd}$ layers. The replicability of this technology was demonstrated by the synthesis of membranes with similar thickness and deviating by only $1 \%$. Furthermore, the multitube membrane module was tested for 842.25 hours at $450^{\circ} \mathrm{C}$ producing a $6 \mathrm{lb} /$ day of high $\mathrm{H}_{2}$ purity in the range of 99.87$98 \%$ throughout the test. The $\mathrm{H}_{2}$ permeance of the membrane was very stable showing values of 8.8 and $8.2 \mathrm{Nm}^{3} \mathrm{~m}^{-2} \mathrm{~h}^{-1}$ bar $^{-0.5}$ under $\mathrm{H}_{2} / \mathrm{N}_{2}$ mixture and syngas, respectively. Furthermore, by neglecting mass transfer resistances, but taking into consideration the nonlinearity of the Sieverts' law, a more realistic average permeance of $16.2 \mathrm{Nm}^{3} \mathrm{~m}^{-2} \mathrm{~h}^{-1} \mathrm{bar}^{-0.5}$ was obtained. The $\mathrm{H}_{2}$ recovery of the module was between 52 
- $64 \%$ and was a function of the volumetric feed flow rate of the gases. Furthermore, it is clear that the membranes developed displayed a reliable performance under adverse industrial conditions such as those presented in this work including medium-high temperatures, high contaminant concentrations and fluctuations in operating parameters. It can be therefore concluded that this technology could be scaled up and seriously considered as a viable option in industrial applications. Furthermore, the developed computational fluid dynamic model (CFD) revealed differences in membrane usage for this seven-tube configuration. The membrane located at the center displayed a reduced efficiency, possibly caused by the presence of the surrounding membranes which increased competition for the $\mathrm{H}_{2}$ available. The surrounding membranes displayed variations in flux for each quadrant of the membrane surface, mainly caused mass transfer phenomena. Finally, it is possible to conclude that multitube membrane systems require specific considerations in scale-up that differ from single tube membrane units.

AcknowledgementThe authors are indebted to the anonymous reviewers as well as Professor Guiver for their insightful remarks and helpful suggestions that resulted in an improvement of the paper's content. The authors also gratefully acknowledge the financial support provided by the U.S. Department of Energy through the project "Engineering Design of Advanced $\mathrm{H}_{2}-\mathrm{CO}_{2} \mathrm{Pd}$ and Pd/Alloy Composite Membrane Separations and Process Intensification" (Award Number: DE-FE0004895).

\section{Nomenclature}

$\varrho \quad$ Density of the gas mixture

$\begin{array}{lll}\varrho & \text { Density of the gas mixture } & \mathrm{kg} / \mathrm{m}^{3} \\ \stackrel{\mathrm{P}}{\mathrm{i}} & \text { Partial pressure of component } i \text { in the reaction zone } & \mathrm{bar}\end{array}$

Da Damkohler number

GHSV Gas hourly space velocity

Mass flux of component $i$

$\mathrm{R}_{\mathrm{s}} \quad$ Ideal gas constant

Hydrogen permeance of the membrane

Temperature

Delta index

Membrane's thickness

Velocity field

External body forces (gravity, electric, etc.)

Identity matrix

Binary diffusion coefficient between components A and B

Molecular weight of component A

Collision integral for diffusion

$\overline{\mathrm{h}}^{-1}$

$\mathrm{mol} / \mathrm{s}$

$\mathrm{J} / \mathrm{K} / \mathrm{mol}$

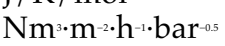

$\mathrm{K}$

$\mu \mathrm{m}$

$\mathrm{m} / \mathrm{s}$

$\mathrm{N}$

$\mathrm{cm}^{2} / \mathrm{s}$

$\mathrm{g} / \mathrm{mol}$

Lennard-Jones potential between molecules A and B

Mass fraction of species

Molar fraction of species

Viscosity of the fluid 


\section{References}

[1] M. Rosen, The prospects for renewable energy through hydrogen energy systems, Journal of Power and Energy Engineering, 2015, 3, 373-377.

[2] U.S. Office of Energy Efficiency and Renewable Energy, Hydrogen production: Natural gas reforming. http://energy.gov/eere/fuelcells/hydrogen-production-natural-gas-reforming

[3] N.A. Al-Mufachi, , N.V. Rees, R. Steinberger-Wilkens, Hydrogen selective membranes: A review of palladium-based dense metal membranes, Renewable and Sustainable Energy Reviews 47 (2015) 540551.

[4] T.M. Nenoff, R.J. Spontak and C.M. Aberg, Membranes for hydrogen purification: An important step toward a hydrogen-based economy, MRS Bulletin 31 (2006) 735-744.

[5] Wellington S.L., Matzakos A.N., Mardilovich I.P., Ma Y.H., Engwall E.E., (2006) Membrane enhanced reactor. US Patent WO 2006034086 A1.

[6] L.C. Ma, B. Castro-Dominguez, N.K. Kazantzis, Y.H. Ma, Integration of membrane technology into hydrogen production plants with $\mathrm{CO}_{2}$ capture: An economic performance assessment study, Int. J. Greenhouse Gas Control 42 (2015) 424-438.

[7] R. Koc, N.K. Kazantzis, Y.H. Ma, Membrane technology embedded into IGCC plants with $\mathrm{CO}_{2}$ capture: An economic performance evaluation under uncertainty, Int. J. Greenhouse Gas Control, 26 (2014) 22-38.

[8] D.F. Sanders, Z.P. Smith, R. Guo, L.M. Robeson, J.E. McGrath, D.R. Paula, B.D. Freeman, Energyefficient polymeric gas separation membranes for a sustainable future: A review, Polymer 54 (2013) 4729-4761.

[9] I.P. Mardilovich, B. Castro-Dominguez, N.K. Kazantzis, T. Wu, Y.H. Ma, A comprehensive performance assessment study of pilot-scale $\mathrm{Pd}$ and $\mathrm{Pd} /$ alloy membranes under extended coal-derived syngas atmosphere testing, Int. J Hydr Energy 40 (2015) 6107-6117.

[10] F. Guazzone, J. Catalano, I.P. Mardilovich, T. Wu, R.C. Lambrecht, S. Datta, J. Kniep, S. Pande, N.K. Kazantzis, and Y.H Ma, Enhancement of the long-term permeance, selectivity stability, and 
recoverability of Pd-Au membranes in coal derived syngas atmospheres, Energy Fuels 27 (2013) 41504160.

[11] C.H. Chen, Y.H. Ma, The effect of $\mathrm{H}_{2} \mathrm{~S}$ on the performance of $\mathrm{Pd}$ and $\mathrm{Pd} / \mathrm{Au}$ composite membrane, J. Memb Sci. 362 (2010) 535-544.

[12] Ø. Hatlevik, S.K. Gade, M.K. Keeling, P.M. Thoen, A.P. Davidson, J.D. Way, Palladium and palladium alloy membranes for hydrogen separation and production: History, fabrication strategies, and current performance, Sep. Purif. Techn. 73 (2010) 59-64.

[13] G.Q. Lu, J.C. Diniz da Costa, M. Duke, S. Giessler, R. Socolow, R.H. Williams, T. Kreutz, Inorganic membranes for hydrogen production and purification: A critical review and perspective, J. Colloid Inter. Sci. 314 (2007) 589-603.

[14] S. Tosti, A. Basile, L. Bettinali, F. Borgognoni, F. Gallucci, C. Rizzello, Design and process study of Pd membrane reactors, Int. J Hydr Energy 33 (2008) 5098-5105.

[15] J.C. Diniz da Costa, G.P. Reed, K. Thambimuthu, High temperature gas separation membranes in coal gasification, Proceedings of the 9th International Conference on Greenhouse Gas Control Technologies 1 (2009) 295-302.

[16] D. Parsley, R.J. Ciora Jr., D.L. Flowers, J.Laukaitaus, A. Chen, P.K.T. Liu, J. Yu, M. Sahimi, A. Bonsu, T.T. Tsotsis, Field evaluation of carbon molecular sieve membranes for the separation and purification of hydrogen from coal- and biomass-derived syngas, J. Memb Sci. 450 (2014) 81-92.

[17] G. He, Y. Mi, P.L. Yue, G. Chen, Theoretical study on concentration polarization in gas separation membrane processes, J. Membr Sci. 153 (1999) 243-258.

[18] M. Coroneo, G. Montante, M. Giacinti Baschetti, A. Paglianti, CFD modeling of inorganic membrane modules for gas mixture separation, Chem. Eng. Sci. 64 (2009)1085-1094.

[19] M. Coroneo, G. Montante, M. Giacinti Baschetti, A. Paglianti, Numerical and experimental fluiddynamic analysis to improve the mass transfer performance of $\mathrm{Pd}-\mathrm{Ag}$ membrane modules for hydrogen purification, Ind. Eng. Chem. Res, 49 (2010) 9300-9309.

[20] L.C. Ma, B. Castro-Dominguez, N.K. Kazantzis, Y.H. Ma, A cost assessment study for a large-scale water gas shift catalytic membrane reactor module in the presence of uncertainty, Sep. Purif. Techn. 166 (2016) 205-212.

[21] P.P. Mardilovich, Y. She and Y.H. Ma, Defect-free Palladium membrane on porous stainless-steel support, AICHE Journal 44 (1998) 310-322. 
[22] Ma YH, Mardilovich IP, Engwall EE. (2007) Composite gas separation modules having high Tamman temperature intermediate layers. US Patent No. 7,255,726.

[23] Ma YH, Mardilovich PP, She Y. (2000) Hydrogen gas-extraction module and method fabrication. US Patent No. 6,152,987.

[24] Ma YH, Mardilovich IP, Engwall EE. (2007) Composite gas separation modules having intermediate porous metal layer. US Patent No. 7,175,694.

[25] Ma YH, Mardilovich IP, Engwall EE. (2008) Method for fabricating composite gas separation modules. US Patent No. 7,390,536.

[26] Ma YH, Mardilovich IP, Engwall EE. (2007) Method for curing defects in the fabrication of a composite gas separation module. US Patent No. 7,172,644.

[27] F. Guazzone , J. Catalano, I.P. Mardilovich, J Kniep, S. Pande, T. Wu, R.C. Lambrecht, S. Datta, N.K. Kazantzis, Y.H. Ma, Gas permeation field tests of composite Pd and Pd-Au membranes in actual coal derived syngas atmosphere, Int. J Hydr Energy 37 (2012) 4557-4568.

[28] J. Boon , J.A.Z. Pieterse, F.P.F. van Berkel, Y.C. van Delft, M. van Sint Annaland, Hydrogen permeation through palladium membranes and inhibition by carbon monoxide, carbon dioxide, and steam, J. Membr. Sci.496 (2015)344-358.

[29] G. He, Y. Mi, P.L. Yue, G. Chen, Theoretical study on concentration polarization in gas separation membrane processes, J. Membr. Sci 153 (1999) 243-258.

[30] S.K. Ryi, S.W. Lee, D.K. Oh, B.S. Seo, J.W. Park, J.S. Park, D.W. Lee, S.S. Kim. Electroless plating of Pd after shielding the bottom of planar porous stainless steel for a highly stable hydrogen selective membrane. J Membr. Sci. 467 (2014) 93-99.

[31] S. Adhikari, S. Fernando, Hydrogen membrane separation techniques, Ind. Eng. Chem. Res. 45 (2006) 875-881.

[32] A.F. Ismail, K. Khulbe, T. Matsuura, Gas separation membranes: Polymeric and inorganic, Springer, Apr 28, 2015 - Science. 